\title{
PRODUÇÃO DE REPOLHO 'Chato de Quintal' E DA CAPUCHINHA 'Jewel', SOLTEIROS E CONSORCIADOS, SEM E COM CAMA-DE-FRANGO SEMIDECOMPOSTA INCORPORADA NO SOLO
}

\author{
Yield of 'Chato de quintal' cabbage and of 'Jewel' nasturtium, in monocrop and intercrop \\ system, with and without semi-decomposed chicken manure added to the soil
}

\author{
Ademir Antunes Moraes ${ }^{1}$, Maria do Carmo Vieira², Néstor Antonio Heredia Zárate ${ }^{3}$
}

\section{RESUMO}

Este trabalho teve como objetivo avaliar a produção de "cabeças" de repolho e de flores de capuchinha. A capuchinha 'Jewel' (Ca) e o repolho 'Chato de Quintal' (R) foram alocados no campo em experimento conjunto, sendo estudados cada um deles como fatorial 2 (cultivos solteiro e consorciado) x 2 (sem-S e com-C cobertura do solo com cama-de-frango, na dose de 6,5 $\mathrm{t} \mathrm{ha}^{-1}$ ), perfazendo, no total, seis tratamentos ( $\mathrm{CaS}, \mathrm{CaC}, \mathrm{RS}, \mathrm{RC}, \mathrm{CaRS}, \mathrm{CaRC})$, arranjados no delineamento experimental de blocos casualizados, com quatro repetições. As colheitas das flores de capuchinha foram efetuadas entre 35 e 98 dias após o transplante (DAT) e a do repolho entre 83 e 104 DAT. A altura das plantas de repolho apresentou crescimento linear, com taxas variáveis, em função dos dias após o transplante, com o uso de cama-de-frango no solo, e com o sistema de cultivo. As produções de repolho foram de $32,76 \mathrm{t} \mathrm{ha}^{-1}$ no arranjo em cultivo solteiro e de $27,65 \mathrm{t} \mathrm{ha}^{-1}$ no cultivo consorciado e de $35,78 \mathrm{t} \mathrm{ha}^{-1}$ e $24,62 \mathrm{t}^{-1} \mathrm{a}^{-1}$, com e sem o uso de cama-de-frango, respectivamente. A maior produção de capuchinha foi sem o uso de cama-de-frango, em cultivo solteiro, com 15.825.000 flores e 10,63 t ha- ${ }^{-1}$ de massa fresca. Altura de plantas, diâmetro e comprimento das flores de capuchinha foram influenciados apenas pelas épocas de avaliação. O cálculo da razão de área equivalente para o consórcio foi de 1,35 com uso de camade-frango e de 1,25 sem o uso, indicando ser viável o cultivo misto de repolho com a capuchinha. A renda bruta para o consórcio foi de $\mathrm{R} \$ 38.065,20$ e $\mathrm{R} \$ 28.587,50$ com e sem uso de cama-de-frango, respectivamente.

Termos para indexação: Brassica oleracea var. capitata, Tropoaeolum majus, associação de espécies, resíduo orgânico, renda.

\begin{abstract}
This work has as objective to study yield of cabbage and nasturtium flowers. 'Jewel' nasturtium (Ca) and 'Chato de quintal' cabbage were placed at field in jointed experiment, and they were studied as 2 (monocrop and intercrop system) 2 (with or without soil covering with chicken manure, in dose of $\left.6.5 \mathrm{t} \mathrm{ha}^{-1}\right)$ factorial scheme, which resulted in six treatments $(\mathrm{CaS}, \mathrm{CaC}, \mathrm{RS}, \mathrm{RS}, \mathrm{CaRS}$, $\mathrm{CaRC}$ ) that were arranged in a randomized block experimental design with four replications. Harvests of nasturtium flowers were done between 35 and 98 days after transplant (DAT) and of cabbage between 83 and 104 DAT. Heights of cabbage plants showed linear growth with variable indexes as a function of days after transplant with the use of chicken manure on soil and with the cultivation system. Yields of cabbage were $32.76 \mathrm{t} \mathrm{ha}^{-1}$ for monocrop arrangement and 27.65 for intercrop system and $35.78 \mathrm{tha}^{-1}$ and $24.62 \mathrm{t} \mathrm{ha}^{-1}$, with and without the use of chicken manure, respectively. The highest yield of nasturtium was without the use of chicken manure, in monocrop system, with 15,825,000 flowers and $10.63 \mathrm{t} \mathrm{ha}^{-1}$ of fresh mass. Plant height, diameter and length of nasturtium flowers were influenced only by evaluation dates. Land Equivalent Ratio calculus for intercrop system was 1.35 with the use of chicken manure and 1.25 without the use, which indicates that cabbage/nasturtium intercropping is viable. Gross income for intercrop system was $\mathrm{R} \$ 38,065.20$ and $\mathrm{R} \$ 28,587.50$ with and without the use of chicken manure, respectively.
\end{abstract}

Index terms: Brassica oleracea var. capitata, Tropaeolum majus, intercropping, organic residue, income.

(Recebido em 11 de agosto de 2005 e aprovado em 26 de setembro de 2006)

\section{INTRODUÇÃO}

O aumento da produtividade por unidade de área é uma das razões mais importantes para se cultivar duas ou mais culturas no sistema de consorciação, o que permite melhor aproveitamento da terra e de outros recursos disponíveis, resultando em maior rendimento econômico. Em solo com culturas mistas ou intercaladas o enraizamento pode ser bom, se as espécies cultivadas combinarem melhorando a cobertura do solo e conseqüentemente diminuindo a radiação solar que o alcança (PRIMAVESI, 1980). Vandermeer (1989) cita que no consórcio a fraca competição está operando quando "uma espécie proporciona algum tipo de benefício para a outra”, alterando o "ambiente da outra espécie positivamente, mas

\footnotetext{
${ }^{1}$ Doutor - Faculdade de Ciências Agrárias/FCA - Universidade Federal da Grande Dourados/UFGD - Rodovia Dourados a Ithaum, Km 12 - Cx. P. 533 79804-970 - Dourados, MS - a.antunes@ufgd.edu.br

2Doutora, Professora Titular - Faculdade de Ciências Agrárias/FCA - Universidade Federal da Grande Dourados/UFGD - Rodovia Dourados a Ithaum, Km 12 - Cx. P. 533 - 79804-970 - Dourados, MS - Bolsista de Produtividade em Pesquisa do CNPq - mcvieira@ufgd.edu.br ${ }^{3}$ Doutor, Professor Associado I - Faculdade de Ciências Agrárias/FCA - Universidade Federal da Grande Dourados/UFGD - Rodovia Dourados a Ithaum, Km 12 - Cx. P. 533 - 79804-970 - Dourados, MS - Bolsista de Produtividade em Pesquisa do CNPq - nheredia@ufgd.edu.br
} 
não necessariamente de maneira recíproca". Fraca competição ocorre quando "as duas culturas utilizam diferentes componentes do ecossistema, ou utilizam o mesmo componente em formas diferentes, ou de algum modo exploram nichos ecológicos distintos". Este princípio é chamado "Princípio da Produção Competitiva" e estabelece que "duas culturas irão produzir mais do que os respectivos monocultivos se a competição mútua for suficientemente fraca".

A capuchinha (Tropaeolum majus L.) é bastante versátil e possui ampla utilização como medicinal, companheira, melífera, corante natural, hortaliça nãoconvencional e ornamental (CORRÊA, 1984). No Brasil, a planta toda é utilizada na medicina popular como antiescorbútica, tônica, expectorante e os frutos secos como purgante (FONT QUER, 1993). Pode ser classificada como hortaliça de folha, flor e haste, já que toda a planta é comestível, possuindo sabor acre e picante, em decorrência de um composto sulforoso, também presente no agrião (Nasturtium officinale). As folhas e flores são ricas em vitamina $\mathrm{C}$ e sais minerais (N, S, I, F, K e fosfatos) (ZURLO \& BRANDÃO, 1989). A espécie é bastante rústica e de fácil cultivo; quando cultivada junto com cucurbitáceas pode atrair lepidópteros e repelir pulgões e besouros (LACABUENDIA \& BRANDÃO, 1988).

O repolho (Brassica oleracea var. capitata) é hortaliça herbácea, com folhas arredondadas e cerosas, formando uma "cabeça" compacta. Ao longo do tempo, foram obtidas cultivares adaptadas a temperaturas elevadas, ampliando conseqüentemente os períodos de plantio e de colheita. Assim, pela escolha criteriosa da cultivar, a época de plantio estende-se ao longo do ano, em diversas regiões produtoras (FILGUEIRA, 2000).

Carneiro (1981), em pesquisa de cultivo misto de repolho e alface verificou que, à medida que aumentava a densidade de plantas ha ${ }^{-1}$, aumentava também o número de cabeças formadas e a produção com poucas diferenças entre os sistemas, misto e solteiro, o que evidenciou que a cultura intercalar não interferiu na formação de cabeças da cultura principal, mesmo em altas densidades. A produção da cultura exclusiva foi superior à cultura mista, em todos os tratamentos, indicando que houve competição entre as plantas estudadas.

Tolentino Júnior et al. (2002) estudaram os monocultivos da mandioquinha-salsa, da beterraba e da alface, além dos consórcios mandioquinha-beterraba e mandioquinha-alface. Os diâmetros das cabeças e as produtividades de massa fresca e seca das plantas de alface não diferiram significativamente entre os cultivos solteiro e consorciado. A produtividade de massa fresca da alface foi de 17,78 e 14,58 $\mathrm{t} \mathrm{ha}^{-1} \mathrm{em}$ cultivo solteiro e consorciado, respectivamente. Quanto à beterraba, houve diferenças significativas entre os cultivos. As produtividades de massas frescas das raízes foram $16,96 \mathrm{t} \mathrm{ha}^{-1}$ para o cultivo solteiro e 10,02 t ha-1 no consorciado. Considerando os valores da razão de área equivalente (RAE) e da renda bruta, concluíram que o consórcio da mandioquinha-salsa com a alface foi viável.

Porto (2004) trabalhou com o consórcio alface e rabanete, buscando conhecer a viabilidade econômica, em função da sazonalidade de preços dessas hortaliças. A produtividade do consórcio, em transplantio simultâneo da alface com a semeadura do rabanete, no espaçamento $0,30 \times 0,30 \mathrm{~m}$ foi de $29.436,50$ e $9.170 \mathrm{~kg} \mathrm{ha}^{-1}$, respectivamente, contra $36.445,00$ e $8.512 \mathrm{~kg} \mathrm{ha}^{-1}$, na semeadura do rabanete quatorze DAT da alface e espaçamento de 0,40 x 0,30 m correspondendo às maiores receitas bruta e líquida, ambas na época de verão.

Santos et al. (2004), avaliando a produtividade, renda bruta e razão de área equivalente de cenoura e rúcula, em sistema de cultivo consorciado, estabelecido aos 0,7 e 14 dias após a semeadura da cenoura e da rúcula em monocultivo, concluíram ser viável o cultivo consorciado dessas plantas. A melhor época para o produtor de rúcula é o estabelecimento do consórcio com a semeadura das duas espécies no mesmo dia. Para o produtor de cenoura, a produção total de raízes foi maior quando a rúcula foi semeada 14 dias após a semeadura da cenoura. Supõe-se que o sistema radicular da rúcula promoveu melhoria das condições físicas do solo e que a presença da planta na entrelinha resultou em menor evaporação superficial, favorecendo a produção.

Moraes et al. (2004) avaliaram a produção de capuchinha e repolho de folhas verde e roxa, em cultivo solteiro e consorciado, com duas e três fileiras de plantas no canteiro. Verificaram que as melhores produções do repolho ocorreram nas plantas em consórcio e que, embora não se tenha detectado significância para o número de fileiras no canteiro, houve maior produção com as plantas sob duas fileiras, alcançando produção de $8,49 \mathrm{t} \mathrm{ha}^{-1} \mathrm{de}$ massa fresca de "cabeça", para o repolho de folhas verdes. A capuchinha cultivada solteira alcançou as maiores produções de flores, sob duas fileiras no canteiro, com 12.022,22 mil flores $\mathrm{ha}^{-1}$. As RAEs para o consórcio repolho verde e capuchinha e repolho roxo e capuchinha, considerando a massa fresca de cabeças de repolho e das flores da capuchinha, foram de 1,76 e 1,60, respectivamente, indicando serem consórcios efetivos. Concluíram que, para

Ciênc. agrotec., Lavras, v. 31, n. 3, p. 731-738, maio/jun., 2007 
o produtor de repolho foi aconselhável o cultivo consorciado, enquanto para o de capuchinha foi o cultivo solteiro.

Os objetivos deste trabalho foram avaliar a produção de "cabeças" de repolho e de flores de capuchinha, cultivadas como culturas solteiras e consorciadas, com e sem uso de cama-de-frango semidecomposta incorporada ao solo.

\section{MATERIAL E MÉTODOS}

O experimento foi conduzido no Horto de Plantas Medicinais, da Universidade Federal de Mato Grosso do Sul, em Dourados-MS, no período de junho a outubro de 2004. O solo é tipo Latossolo Vermelho distroférrico, de textura argilosa. As características químicas do solo foram: pH em água (1:2,5): 4,8; $\mathrm{Al}^{+3}, \mathrm{~K}, \mathrm{Mg}$ e $\mathrm{Ca}\left(\mathrm{mmol}_{\mathrm{c}} \cdot \mathrm{dm}^{-3}\right): 3,8$; 6,$1 ; 8,6$ e 13,3; P (mg.dm $\left.{ }^{-3}\right)$ : 13,0; soma de bases: 28,0 mmol ${ }_{\mathrm{c}} \cdot \mathrm{dm}^{-3}$; capacidade de troca de cátions: 172,0 mmol $\cdot \mathrm{dm}^{-3}$ e saturação de bases: $39,2 \%$ e matéria orgânica $\left(\mathrm{g} . \mathrm{kg}^{-1}\right): 25,9$. A composição da cama-de-frango $\left(\mathrm{g} \mathrm{kg}^{-1}\right)$ foi de 205,6; 28,5; 24,3 e 18,7 para $\mathrm{C}_{\text {orgânico }}, \mathrm{P}_{\text {total }}, \mathrm{K}_{\text {total }}$ e $\mathrm{N}_{\text {total }}$ ' respectivamente, e relação $\mathrm{C} / \mathrm{N}=10,99$.

A capuchinha 'Jewel' (Ca) e o repolho 'Chato de Quintal' (R) foram alocados no campo em experimento conjunto, sendo estudados cada um deles como fatorial 2 (cultivos solteiro e consorciado) x 2 (sem-S e com-C cobertura do solo com cama-de-frango, na dose de 6,5 $\mathrm{t} \mathrm{ha}^{-1}$ ), perfazendo, dessa forma, no total, seis tratamentos. $\mathrm{O}$ arranjo dos tratamentos (CaS, CaC, RS, RC, CaRS, CaRC) foi no delineamento experimental de blocos casualizados, com quatro repetições. As parcelas tinham área total de $3,15 \mathrm{~m}^{2}$ (1,50 m de largura por 2,10 m de comprimento) e área útil totalizando $2,27 \mathrm{~m}^{2}(1,08 \mathrm{~m} \times 2,10 \mathrm{~m})$. As espécies foram cultivadas em canteiros, sendo a capuchinha sob três fileiras de plantas, com espaçamento de $0,36 \mathrm{~m}$ entre elas, perfazendo população de 65.934 plantas ha $^{-1}$ e o repolho, sob duas fileiras, com espaçamento de $0,36 \mathrm{~m}$ e população de 43.956 plantas ha-1. O espaçamento entre plantas foi de $0,30 \mathrm{~m}$.

O terreno foi preparado com aração, gradagem e levantamento de canteiros com rotoencanteirador. Antes da segunda passagem do rotoencanteirador foi efetuada a incorporação da cama-de-frango, nas respectivas parcelas. As semeaduras do repolho e da capuchinha foram efetuadas em bandejas de isopor de 128 células, com uso de substrato vegetal comercial, em 16/06/2004, simultaneamente. Quando as plantas apresentavam altura média de $7,0 \mathrm{~cm}$ e quatro a cinco folhas, foram transplantadas ao local definitivo, o que ocorreu aos 23 dias após a emergência. As irrigações foram feitas utilizando o sistema de aspersão, com turnos de rega a cada dois dias. As capinas foram manuais, em número de duas. Durante o ciclo de cultivo, foram medidas as alturas das plantas de repolho e capuchinha, com ajuda de uma régua graduada em centímetros, entre 25 a 67 dias após o transplante - DAT, com intervalo de sete dias. As colheitas das flores de capuchinha foram efetuadas entre 35 a 98 DAT e a das "cabeças"de repolho entre 83 a 104 DAT, com intervalo de três dias.

As características avaliadas do repolho foram diâmetro da planta, diâmetro e altura da "cabeça" e produções de massas fresca e seca das cabeças. Para medir o diâmetro foi adaptado um paquímetro, com ajuda de uma régua e duas canetas, sendo uma fixa e outra móvel. A altura da "cabeça" foi determinada desde a base até o ápice, após sua separação das folhas não compactadas, com ajuda de uma régua graduada, em centímetros. Da capuchinha, foram avaliados o número total de flores; massas frescas e secas de flores. O comprimento e diâmetro das flores foram medidos entre 30 e 51 DAT, no intervalo de sete dias, com ajuda de um paquímetro, em milímetros.

Os dados de cada espécie foram submetidos à análise de variância e testados pelo teste $\mathrm{F}$, até $5 \%$ de probabilidade (RIBEIRO JÚNIOR, 2001). Às médias de altura de plantas, comprimento e diâmetro de flores foram ajustadas equações de regressão, até $5 \%$ de probabilidade (BANZATTO \& KRONKA, 1989; RIBEIRO JÚNIOR, 2001).

O consórcio foi avaliado utilizando a expressão da razão de área equivalente (RAE) proposta por Caetano et al. (1999), a saber: RAE $=\mathrm{Rc} \cdot \mathrm{Rs}^{-1}+\mathrm{Cc} \cdot \mathrm{Cs}^{-1}$, onde, respectivamente, $\mathrm{Rc}$ e $\mathrm{Cc}=$ massas frescas de "cabeças" comerciais de repolho e de flores de capuchinha em consorciação e Rs e Cs = massas frescas de "cabeças" comerciais de repolho e de flores de capuchinha em cultivo solteiro. A validação do consórcio foi realizada mediante a determinação da renda bruta que poderia ser obtida com a venda das "cabeças" de repolho e das flores de capuchinha. Para isso, foram entrevistados vários vendedores de repolho, em abril de 2005, em vários locais de venda no varejo de Dourados, obtendo-se a informação de que o preço pago ao produtor de repolho era de $\mathrm{R} \$ 0,83 \mathrm{~kg}^{-1}$ de “cabeça". Para a capuchinha foi feita uma estimativa de preço de venda, correspondendo a $\mathrm{R} \$ 0,20$ por caixa com 100 flores.

\section{RESULTADOS E DISCUSSÃO}

\section{Crescimento e produção do repolho}

A altura das plantas de repolho apresentou crescimento linear, com taxas variáveis, em função dos dias 
após o transplante, com o uso de cama-de-frango no solo, e com o sistema de cultivo (Figura 1). Esses resultados indicam que as taxas variáveis de crescimento e a morfologia bem característica das plantas, com modificações durante o ciclo vegetativo, têm relação com o padrão de resposta da espécie a fatores ambientes (HEREDIA ZÁRATE, 1988). O uso da cama-de-frango no

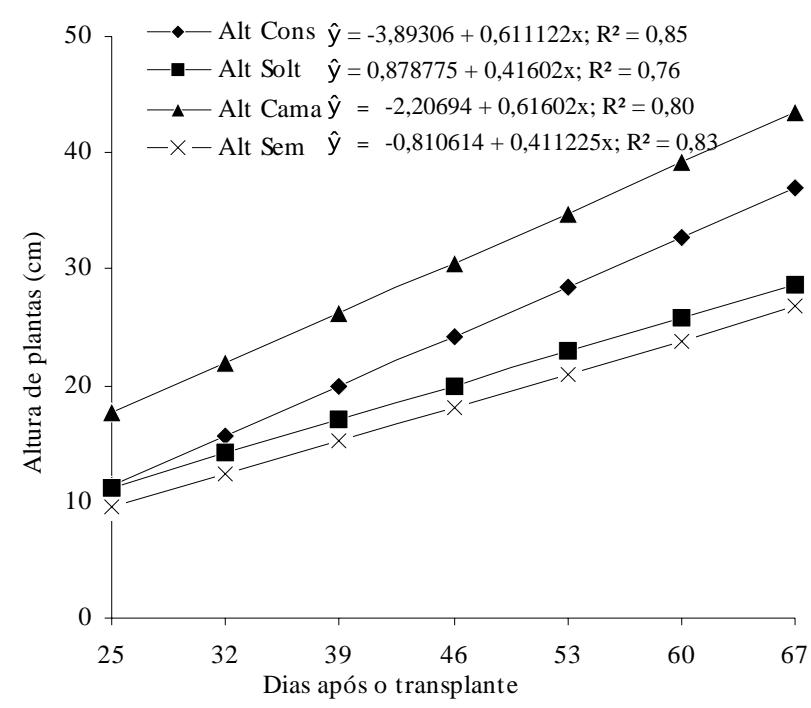

FIGURA 1 - Crescimento em altura das plantas de repolho 'Chato de quintal', em cultivo solteiro (SOLT) e consorciado (CON) com a capuchinha 'Jewel', com (CAMA) ou sem (SEM) o uso de cama-de-frango no solo. UFMS, Dourados, 2004. solo induziu as maiores alturas das plantas de repolho, provavelmente, por ter propiciado maior quantidade de água e de nutrientes disponíveis no solo (KIEHL, 1985). Em relação ao sistema de cultivo, as maiores alturas das plantas foram das consorciadas. Isso, provavelmente, por haver menos luz disponível, o que induziu às plantas recorrerem a alguns mecanismos fisiológicos para se adaptarem à competição, dentre eles, o aumento da altura, visando expor a superfície para maior interceptação e absorção de luz (LARCHER, 2000; VIEIRA, 1989).

$\mathrm{O}$ diâmetro das plantas de repolho foi influenciado significativamente pelo sistema de cultivo e as produções de massas fresca e seca, pelo uso de cama-de-frango no solo (Tabela 1). As plantas cultivadas solteiras, em relação às consorciadas, apresentaram diâmetro significativamente maiores em 8,25 cm mas com semelhança estatística no diâmetro das "cabeças" e nas produções de massa fresca e seca. Isso indica que os sistemas vegetais são capazes de se auto-regular, baseando-se na capacidade de adaptação do organismo individual e das populações (LARCHER, 2000), relacionado às diferenças no crescimento e desenvolvimento das plantas, até alcançar o ponto de colheita (TOLENTINO JÚNIOR et al., 2002).

A cama-de-frango no solo induziu aumentos de $11,16 \mathrm{t} \mathrm{ha}^{-1}$ de massa fresca e $0,58 \mathrm{t} \mathrm{ha}^{-1}$ de massa seca de repolho, em relação ao solo sem cama. Esses resultados devem ter relação com o fato de que os adubos orgânicos contêm vários nutrientes minerais, especialmente $\mathrm{N}, \mathrm{P}$ e K, e embora sua concentração seja considerada baixa, na sua valorização, deve-se levar em conta, também, o efeito benéfico que exercem sobre o solo (FORNASIERI FILHO,

TABELA 1 - Diâmetro das plantas e das “cabeças" e produções de massas fresca e seca do repolho 'Chato de quintal', em cultivo solteiro e consorciado com a capuchinha 'Jewel', com ou sem uso de cama-de-frango no solo. UFMS, Dourados, 2004.

\begin{tabular}{lcccc}
\hline Parâmetro & \multicolumn{2}{c}{ Diâmetro $(\mathbf{c m})$} & \multicolumn{2}{c}{ Massa (t ha $\left.{ }^{-1}\right)$} \\
\cline { 2 - 5 } & Planta & "Cabeça" & Fresca & Seca \\
\hline Tipo de cultivo & & & & $2,15 \mathrm{a}$ \\
\hline Solteiro & $64,85 \mathrm{a}$ & $16,72 \mathrm{a}$ & $32,76 \mathrm{a}$ & $1,60 \mathrm{a}$ \\
Consorciado & $56,65 \mathrm{~b}$ & $16,17 \mathrm{a}$ & $27,65 \mathrm{a}$ & $2,17 \mathrm{a}$ \\
\hline Cama-de-frango no solo & & & & $1,59 \mathrm{~b}$ \\
\hline Com cama & $62,40 \mathrm{a}$ & $17,35 \mathrm{a}$ & $35,78 \mathrm{a}$ & 26,59 \\
Sem cama & $59,09 \mathrm{a}$ & $15,54 \mathrm{a}$ & $24,62 \quad \mathrm{~b}$ &
\end{tabular}

Médias seguidas pelas mesmas letras, nas colunas, não diferem pele teste $\mathrm{F}$, a $5 \%$ de probabilidade. 
1992). A matéria orgânica dos resíduos decompostos ativa os processos microbianos (SILVA JÚNIOR \& SIQUEIRA, 1997), fomentando, simultaneamente, a estrutura, a aeração e a capacidade de retenção de água. Atua ainda como reguladora da temperatura do solo, retarda a fixação do $\mathrm{P}$ mineral e fornece produtos da decomposição orgânica que favorecem o desenvolvimento da planta. A atividade dos micro-organismos do solo, que sintetizam e decompõem a matéria orgânica, disponibilizam o nitrogênio, que no solo ocorre, principalmente, na forma orgânica ( $95 \%$ de N total) (FORNASIERI FILHO, 1992).

\section{Crescimento e produção da capuchinha}

A altura das plantas da capuchinha não foi influenciada significativamente pelos fatores em estudo. Houve crescimento linear da altura das plantas indicando que foi característica da cultivar 'Jewel'. Ferreira (2000), ao estudar espaçamentos entre plantas, na mesma cultivar de capuchinha, observou que o crescimento foi lento até os 30 DAT e a partir daí houve incrementos na altura das plantas, com taxas crescentes, até os 75 dias, para o espaçamento de 0,20 m entre plantas, e até 90 dias, para 0,30 e 0,40 m.

$\mathrm{O}$ diâmetro e o comprimento das flores de capuchinha apresentaram crescimento quadrático mas não foram influenciados significativamente pelos fatores em estudo. Estes resultados vão de encontro ao exposto por Larcher (2000), de que o padrão de resposta de uma planta e seu potencial específico de adaptação durante o seu período de crescimento é característica geneticamente determinada. $\mathrm{O}$ diâmetro e o comprimento máximo das flores foram alcançados aos 38 DAT, sendo de $56 \mathrm{~mm}$ e $62 \mathrm{~mm}$, respectivamente. Esses resultados são diferentes daqueles obtidos por Sangalli (2002), que estudando o crescimento e a produção de capuchinha 'Jewel', na mesma área experimental, encontrou valores de 42,7 a 45,7 mm para o diâmetro da flor e de 25 a 26 mm para o comprimento, entre 70 e 98 DAT. As diferenças podem estar relacionadas com as diferenças nas épocas de avaliação. Por outro lado, os valores encontrados foram semelhantes aos de Barbosa (2004), que foram de 51 e $61 \mathrm{~mm}$ de diâmetro e comprimento, respectivamente.

O número e a massa fresca de flores de capuchinha foram influenciados significativamente apenas pelo tipo de cultivo (Tabela 2). O maior número (13.298.500 flores) e as maiores massas frescas $\left(8,86 \mathrm{t} \mathrm{ha}^{-1}\right)$ e secas $\left(0,70 \mathrm{t} \mathrm{ha}^{-1}\right)$ de flores foram obtidos no cultivo solteiro. Esses resultados indicam que houve melhor adaptabilidade das plantas solteiras, provavelmente relacionada com a manutenção da eficiência na absorção e/ou, no uso da água, dos nutrientes e do $\mathrm{CO}_{2}$, já que, na maioria das culturas consorciadas é notada redução de produtividade (SILVA, 1983). Isso porque os sistemas ecológicos são capazes de auto-regulação e essa capacidade baseia-se no equilíbrio das relações de interferência (LARCHER, 2000), principalmente, em um sistema de culturas múltiplas, geralmente formado por espécies diferentes, onde encontram-se raízes que exploram o solo a diferentes profundidades (SILVA, 1983), ou onde as folhas podem responder diferencialmente à competição por luz (HARDER, 2004). Moraes et al. (2004), estudando a produção da capuchinha 'Jewel' em cultivo solteiro e consorciado com repolhos de folhas verde ou roxa, em arranjos de duas e três fileiras no canteiro, observaram que a capuchinha solteira, com duas fileiras, alcançou produção de $8,20 \mathrm{t} \mathrm{ha}^{-1}$ de massa fresca, contra 5,04 tha ${ }^{-1}$ no consórcio com arranjo de três fileiras de capuchinha e duas de repolho roxo.

\section{Avaliação do consórcio}

As razões de área equivalente (RAE) foram de 1,35 e 1,25 para os consórcios repolho e capuchinha, cultivados em solo com e sem cama-de-frango, respectivamente, indicando que foi eficiente esse sistema de cultivo (Tabela 3). Moraes et al. (2004) encontraram a RAE de 1,76 e 1,60, respectivamente, para o consórcio repolho verde e capuchinha e repolho roxo e capuchinha, considerando a massa fresca de cabeças de repolho e das flores de capuchinha. Esses resultados mostram que os consórcios foram efetivos e coerentes com o "princípio da produção competitiva", quando estabelece que "duas culturas irão produzir mais do que os respectivos monocultivos ('overyield') se a competição mútua for suficientemente fraca” (SANTOS, 1998).

Ao analisar a renda bruta, observou-se que para os produtores de repolho e de capuchinha foi melhor quando utilizou cama-de-frango, incorporada no solo, porque poderia ter induzido ganho de $\mathrm{R} \$ 9.477,70$ em relação ao consórcio sem cama-de-frango (Tabela 3). No entanto, o consórcio sem cama-de-frango no solo, quando comparado com o cultivo solteiro do repolho com cama-de-frango não foi viável em relação aos cultivos solteiros. Para o produtor de capuchinha, o consórcio com cama-de-frango no solo foi viável em relação aos cultivos solteiros.

Os valores obtidos para as RAEs e para as rendas brutas mostram-se coerentes com as citações de Harder (2004), Heredia Zárate et al. (2003), Salvador (2003) e Sullivan (2003), de que o aumento da produtividade por unidade de área é uma das razões mais importantes para se cultivar duas ou mais culturas no sistema de consorciação, porque permite melhor aproveitamento da terra e de outros recursos disponíveis. 
TABELA 2 - Número de flores e produção de massas fresca e seca de flores de capuchinha 'Jewel', em cultivo solteiro e consorciado com o repolho 'Chato de Quintal', com ou sem uso de cama-de-frango no solo. UFMS. Dourados-MS, 2004.

\begin{tabular}{lccc}
\hline Parâmetro & Número $\left(\mathbf{m i l ~ h a}^{-1}\right)$ & \multicolumn{2}{c}{ Massa $\left(\mathbf{t ~ h a}^{-1}\right)$} \\
\cline { 3 - 3 } & & & Seca \\
\hline Tipo de cultivo & & $8,86 \mathrm{a}$ & $0,70 \mathrm{a}$ \\
\hline Solteiro & $13298,50 \mathrm{a}$ & $3,47 \mathrm{~b}$ & $0,27 \mathrm{~b}$ \\
Consorciado & $5190,17 \mathrm{~b}$ & & $0,44 \mathrm{a}$ \\
\hline Cama-de-frango no solo & & $5,67 \mathrm{a}$ & $0,52 \mathrm{a}$ \\
\hline Com cama & $7294,33 \mathrm{a}$ & $6,66 \mathrm{a}$ & 39,12 \\
\hline Sem cama & $9994,33 \mathrm{a}$ & 41,64 & \\
\hline C.V. $(\%)$ & 45,00 & & \\
\hline
\end{tabular}

Médias seguidas pelas mesmas letras, nas colunas, não diferem pele teste $\mathrm{F}$, a $5 \%$ de probabilidade.

TABELA 3 - Razão de área equivalente (RAE) e Renda bruta, considerando a produção de massa fresca do repolho 'Chato de quintal' e do número de flores de capuchinha 'Jewel', em cultivo solteiro e consorciado, com e sem uso de cama-de-frango no solo. UFMS. Dourados, 2004.

\begin{tabular}{|c|c|c|c|c|c|c|c|}
\hline \multirow[t]{2}{*}{ Cultivo } & \multirow[t]{2}{*}{ Espécie } & \multirow{2}{*}{$\begin{array}{c}\text { Uso de } \\
\text { Cama-de } \\
\text { frango }\end{array}$} & \multirow{2}{*}{$\begin{array}{c}\text { Massa fresca } \\
\left(\mathrm{t} \mathrm{ha}^{-1}\right)\end{array}$} & \multirow{2}{*}{$\begin{array}{c}\text { Flores } \\
\left(\text { Mil ha }^{-1}\right)\end{array}$} & \multirow[t]{2}{*}{$\mathbf{R A E}^{1}$} & \multicolumn{2}{|c|}{ Renda bruta $^{2}(\mathrm{R} \$)$} \\
\hline & & & & & & Cultivo & Total \\
\hline \multirow[t]{4}{*}{ Solteiro } & Repolho & Com & 40,92 & -- & 1,00 & $33.963,60$ & $33.963,60$ \\
\hline & & Sem & 24,58 & -- & 1,00 & $20.401,40$ & $20.401,40$ \\
\hline & Capuchinha & Com & & 10.772 & 1,00 & $21.544,00$ & $21.544,00$ \\
\hline & & Sem & & 15.825 & 1,00 & $31.650,00$ & $31.650,00$ \\
\hline \multirow[t]{2}{*}{ Consórcio 1} & Repolho & Com & 30,64 & -- & & $25.431,20$ & \\
\hline & Capuchinha & Com & & 6.317 & 1,35 & $12.634,00$ & $38.065,20$ \\
\hline \multirow[t]{2}{*}{ Consórcio 2} & Repolho & Sem & 24,65 & -- & & $20.459,50$ & \\
\hline & Capuchinha & Sem & & 4.064 & 1,25 & $8.128,00$ & $28.587,50$ \\
\hline
\end{tabular}

${ }^{1}$ Razão de área equivalente ${ }^{2}$ Preço pago ao produtor: $\mathrm{R} \$ 0,83$ por kg de repolho e $\mathrm{R} \$ 0,20$ por caixa com 100 flores de capuchinha. Fonte: Vendedores de hortaliças de Dourados-MS, em abril de 2005.

\section{CONCLUSÕES}

Pelos resultados obtidos, nas condições em que foi conduzido o experimento, concluiu-se que os consórcios de repolho com capuchinha foram viáveis. Considerando a RAE e a renda bruta, o consórcio de repolho e de capuchinha, com as plantas cultivadas em solo com cama-de-frango incorporada, deve ser recomendado.

\section{REFERÊNCIAS BIBLIOGRÁFICAS}

BANZATTO, D. A.; KRONKA, S. Experimentação agrícola. Jaboticabal: FUNEP, 1989. 247 p.

BARBOSA, V. C. Fósforo e resíduo orgânico na produção de biomassa de Tropaeolum majus L. 2004. 19 f.
Dissertação (Mestrado em Agronomia) - Universidade Federal de Mato Grosso do Sul, Dourados, 2004.

CAETANO, L. C. S.; FERREIRA, J. M.; ARAÚJO, M. de. Produtividade da alface e cenoura em sistema de consorciação. Horticultura Brasileira, Brasília, v. 17, n. 2, p. 143-146, 1999.

CARNEIRO, I. F. Competição entre a cultura do repolho (Brassica oleracea var. capitata L.) e a cultura da alface (Lactuca sativa L.) em cultivo misto e em diferentes densidades de população. 1981. 69 f. Dissertação (Mestrado em Fitotecnia) - Escola Superior de Agricultura "Luiz de Queiroz”, Universidade de São Paulo, Piracicaba, 1981. 
CORRÊA, M. P. Dicionário de plantas úteis e das exóticas cultivadas. Rio de Janeiro: Imprensa Nacional, 1984. v. 1.

FERREIRA, R. B. G. Crescimento, desenvolvimento e produção de flores e de frutos de capuchinha 'Jewel' em função de populações e de arranjos de plantas. 2000. $34 \mathrm{f}$. Dissertação (Mestrado em Agronomia) - Universidade Federal de Mato Grosso do Sul, Dourados, 2000.

FILGUEIRA, F. A. R. Novo manual de olericultura: agrotecnologia moderna na produção e comercialização de hortaliças. Viçosa: UFV, 2000. 402 p.

FONT QUER, P. Plantas medicinales: el dioscórides renovado. Barcelona: Editorial Labor, 1993. v. 2, 637 p.

FORNASIERI FILHO, D. A cultura do milho. Jaboticabal: FUNEP, 1992. 273 p.

HARDER, W. C. Produção e renda bruta de rúcula (Eruca sativa Mill.) 'Cultivada' e de almeirão (Cichorium intybus L.) 'Amarelo', em cultivo solteiro e consorciado. 2004. 26 f. Dissertação (Mestrado) - Universidade Federal de Mato Grosso do Sul, Dourados, 2004.

HEREDIA ZÁRATE, N. A. Curvas de crescimento de inhame (Colocasia esculenta (L.) Schott) considerando cinco populações, em solo seco e alagado. 1988. 95 f. Tese (Doutorado em Fitotecnia) - Universidade Federal de Viçosa, Viçosa, 1988.

HEREDIA ZÁRATE, N. A.; VIEIRA, M. C.; WEISMANN, M.; LOURENÇÃO, A. L. F. Produção e renda bruta de cebolinha e salsa em cultivo solteiro e consorciado Horticultura Brasileira, Brasília, v. 21, n. 3, p. 574-577, 2003.

KIEHL, E. J. Fertilizantes orgânicos. Piracicaba: Agronômica Ceres, 1985. 492 p.

LACA-BUENDIA, J. P.; BRANDÃO, M. Usos pouco conhecidos de plantas daninhas como companheiras, repelentes, inseticida, iscas, moluscolinicidas e nematicidas. Informe Agropecuário, Belo Horizonte, v. 13, n. 150 , p. 30-33, 1988.

LARCHER, W. Ecofisiologia vegetal. São Carlos: RiMA Artes e Textos, 2000. 531 p.
MORAES, A. A.; VIEIRA, M. C.; HEREDIA-ZÁRATE, N. A. Produção de repolho e de capuchinha, solteiros e consorciados, com duas ou três fileiras no canteiro. Horticultura Brasileira, Brasília, v. 22, n. 2, jul. 2004. Suplemento. CD-ROM.

PORTO, D. R. Q. Viabilidade econômica do consórcio alface e rabanete, em função da sazonalidade de preços. Horticultura Brasileira, Brasília, v. 22, n. 2, jul. 2004. Suplemento. CD-ROM.

PRIMAVESI, A. O manejo ecológico do solo: agricultura em regiões tropicais. São Paulo: Nobel, 1980. 541 p.

RIBEIRO JÚNIOR, J. I. Análises estatísticas no SAEG. Viçosa: UFV, 2001. 301 p.

SALVADOR, D. J. Produção e renda bruta de cebolinha e de almeirão em cultivo solteiro e consorciado. 2003. $16 \mathrm{f}$. Monografia (Bacharelado em Ciências Biológicas) Universidade Federal do Mato Grosso do Sul, Dourados, 2003.

SANG A LLI, A .Crescimento e produção de Tropaeolum majus L. em função de composto e cama-de-aviário. 2002. 27 f. Dissertação (Mestrado em Agronomia) - Universidade Federal de Mato Grosso do Sul, Dourados, 2002.

SANTOS, R. H. S. Interações interespecíficas em consórcio de olerícolas. 1998. 124 f. Tese (Doutorado em Fitotecnia) - Universidade Federal de Viçosa, Viçosa, 1998.

SANTOS, H. S.; CÂMARA, F. L. A.; VASCONCELLOS, M. C. Produtividade, renda bruta e razão de área equivalente de cenoura e rúcula, em sistema de consórcio e monocultura. Horticultura Brasileira, Brasília, v. 22, n. 2, jul. 2004. Suplemento. CD-ROM.

SILVA, N. F. da. Consórcio de hortaliças. In: HEREDIA, M. C. V.; CASALI, V. W. D. (Coords.). Seminários de olericultura. Viçosa: UFV, 1983. v. 3, p. 1-19.

SILVA JÚNIOR, J. P. da; SIQUEIRA, J. O. Aplicação de formononetina sintética ao solo como estimulante da formação de micorriza no milho e na soja. Revista Brasileira de Fisiologia Vegetal, Brasília, v. 9, n. 1, p. 3541, 1997. 
SULLIVAN, P. Intercropping principles and production practices. Fayetteville: ATTRA, 2003. 12 p. Disponível em: <http://www.attra.org/attra-pub/PDF/intercrop.pdf>. Acesso em: 1 nov. 2004.

TOLENTINO JÚNIOR, C. F.; HEREDIA ZÁRATE, N. A.; VIEIRA, M. C. Produção da mandioquinha-salsa consorciada com alface e beterraba. Acta Scientiarum: Agronomy, Maringá, v. 24, n. 5, p. 1447-1454, 2002.
VANDERMEER, J. H. The ecology of intercropping. Cambridge: Cambridge University, 1989. 237 p.

VIEIRA, C. O feijão em cultivos consorciados. Viçosa: Imprensa Universitária, 1989. 134 p.

ZURLO, C.; BRANDÃO, M. As ervas comestíveis. Rio de Janeiro: Globo, 1989. 167 p. 